\title{
O mundo e o conhecimento sustentável indígena
}

\author{
The world and sustainable indigenous knowledge
}

André Fernando

Diretor da Federação das Organizações Indígenas do rio Negro

Av. Álvaro Maia, 79 69750-000 São Gabriel da Cachoeira - AM - Brasil andrebaniwa@foirn.org.br
FERNANDO, André. O mundo e o conhecimento sustentável indígena. História, Ciências, Saúde - Manguinhos, Rio de Janeiro, v.14, suplemento, p.323-327, dez. 2007.

Para o líder da etnia Baniwa, o ‘mundo sustentável' do ponto de vista dos povos indígenas existe anteriormente à chegada dos colonizadores. O homem branco altera a natureza e por isso o mundo será destruído pelo chamado aquecimento global. É preciso reagir. André Fernando ressalta que no rio Negro foram demarcadas terras indígenas para 22 povos diferentes, o que representa mais de 10,6 milhões de hectares, e que as organizações indígenas têm desenvolvido projetos nessas terras, resultando no Programa Regional de Desenvolvimento Indígena Sustentável do Rio Negro. Os Baniwa participam de seminários para discutir a proteção do acesso aos

conhecimentos tradicionais no Conselho Nacional de Gestão de Patrimônio Genético, e André reivindica do Estado brasileiro respeito à Convenção da Diversidade Biológica, que fala dos direitos indígenas.

PALAVRAS-CHAVE: mitologia; etnia Baniwa; rio Negro; Amazonas; sustentabilidade.

FERNANDO, André. The world and sustainable indigenous knowledge. História, Ciências, Saúde - Manguinhos, Rio de Janeiro, v.14, supplement, p.323-327, Dec. 2007.

For the leader of the Baniwa ethnic group, and from the viewpoint of indigenous peoples, the 'sustainable world' existed even before the colonizers arrived. For Fernando, the white man changes nature, and the world will be destroyed by global warming. He points out that over 10.6 million hectares along the Negro river were demarcated as indigenous lands for 22 different peoples. Indigenous organizations have developed projects on these lands under the Programa Regional de Desenvolvimento Indígena Sustentável do Rio Negro (Regional Program for the Sustainable Indigenous Development of the Negro River). At the Conselho Nacional de Gestão de Patrimônio Genético (National Council on the Management of Genetic Heritage), the Baniwa take part in seminars where they discuss the protection of access to traditional knowledge. Fernando calls on the Brazilian government to respect the Convention on Biological Diversity, which addresses indigenous rights.

KEYWORDS: mythology; Baniwa ethnic group; Negro river; Amazonas; sustainability. 
$\mathrm{O}$ 'mundo sustentável' dos povos indígenas já existia antes da chegada dos colonizadores. Por isso talvez seja difícil para nós, com os nossos conhecimentos, aceitar esse ideal de 'sustentá$v^{v e l}$ '. Os conhecimentos tradicionais dos povos indígenas, no Brasil e no mundo, sempre foram adequados à realidade em que viviam, mas esses conhecimentos foram muito alterados pelo povo não-indígena. Esse povo não-indígena é branco (yalanawinai, em Baniwa) e é dominante no mundo que deveria ser sustentável.

Os brancos não se restringem à alteração dos conhecimentos. Eles roubavam e ainda roubam esses conhecimentos, além de matar muitos povos desta terra. Alteraram a natureza, que para nós é como uma casa que deveria ser cuidada. Hoje, como conseqüência, o mundo vê que seu destino é a destruição, com o chamado aquecimento global cada vez mais real.

Quem é responsável por isso? O mundo capitalista. Mas o fato é que o mundo vai acabar mesmo! Na mitologia Baniwa também existe essa previsão: os mais poderosos de hoje podem ser os mais pobres de amanhã. Ao falar das conquistas, nossa mitologia mostra que esse 'acabar o mundo' equivale a uma inversão de valores. Para os Baniwa, a terra foi criada pelo Heeko, e ele continua vendo o que está se passando aqui. Os homens não cuidam de si, destroem a si mesmos quando acham que estão 'bem de vida' neste mundo.

Para nós, hoje, o 'mundo sustentável' está relacionado exatamente à proteção de nossos conhecimentos, o que historicamente tem significado a sua 'não-declaração', o 'não-registro' desses conhecimentos nos livros e em outros meios de divulgação. Acontece que assim, nós indígenas ficamos desconhecidos, permitindo interpretações absurdas sobre nós. Hoje, muitos de nós estão registrando seus conhecimentos tradicionais como forma de serem conhecidos e respeitados como são. Isso também ajudará a preservar os que estão ameaçados de acabar definitivamente.

Todos os nossos conhecimentos se relacionam com a natureza e são nossos patrimônios, nenhum deles está isolado, do ponto de vista dos povos indígenas. Mas constantemente estão ameaçados pelo mercado que promove a novidade, a novidade que acaba com os outros, que não valoriza o total como é a natureza.

\section{Garantia}

Os conhecimentos tradicionais indígenas são milenares e continuarão existindo enquanto os povos existirem nas suas terras demarcadas, pois os povos são a base dos conhecimentos. Nosso mundo é composto pelas florestas, pelos animais e minerais, além da parte espiritual que temos sobre cada uma dessas partes.

No rio Negro foram demarcadas seis terras indígenas para 22 povos diferentes, faltando ainda reconhecer mais duas terras 
requeridas. As terras indígenas demarcadas e homologadas nos anos de 1997 e 1998 representam mais de 10,6 milhões de hectares. Essa é uma garantia de que os povos e seus conhecimentos continuarão vivos, passando de geração a geração. A Federação das Organizações Indígenas do Rio Negro (Foirn), em parceria com o Instituto Socioambiental (ISA), tem desenvolvido alguns projetos com sucesso nestas terras, o que resultou no Programa Regional de Desenvolvimento Indígena Sustentável do Rio Negro (PRDIS-RN).

Os jovens indígenas, através de escolas próprias, com metodologia de ensino e por meio de pesquisa, estão acessando novamente os conhecimentos tradicionais que são de cada povo, segundo sua organização política. Muitos jovens já são conscientes a ponto de valorizar seus conhecimentos, e isso é muito importante para os povos indígenas do rio Negro, porque é fundamental para um entendimento do outro mundo, o mundo diferente. Isto também é uma garantia de que esses conhecimentos continuarão presentes nas pessoas.

Outra forma de permanecer consiste em registrar esses conhecimentos como patrimônio cultural brasileiro - por exemplo, o registro do lugar sagrado da cachoeira de Iauaretê, no rio Uaupés. Com isso se protegem muitos conhecimentos espirituais que são fundamentais na organização e na saúde das comunidades indígenas.

Depois da demarcação de nossas terras começamos a controlar a ação dos pesquisadores no rio Negro. Criamos critérios básicos para termos uma boa relação com os pesquisadores, e isso realmente tem facilitado a nossa relação.

\section{Participações e discussões}

A partir de projetos concretos, por exemplo, o Rio Negro Através da Arte Baniwa, nós Baniwa estamos participando de seminários que discutem a proteção do acesso aos conhecimentos tradicionais no âmbito do Conselho Nacional de Gestão do Patrimônio Genético (CNGen). Mas na formulação de leis, nós indígenas nunca fomos convidados para participar. Essa participação a que me refiro aconteceu depois de ter sido criada a Medida Provisória de Acesso a Recursos Genéticos e Proteção de Conhecimentos Tradicionais, que vigora até hoje.

A Coordenação das Organizações Indígenas da Amazônia Brasileira (Coiab), que representa o movimento indígena da Amazônia Brasileira, e outros como o Instituto Indígena Brasileiro para Propriedade Intelectual (Inbrapi) têm participação intensiva e significativa nesse processo. E têm promovido discussões sobre a proteção do conhecimento e sobre o consentimento livre e informado, buscando a repartição de benefícios entre as lideranças e comunidades indígenas junto ao ISA e ao Ministério do Meio Ambiente (MMA). 
No estado do Amazonas têm se realizado conferências de pajés com objetivo de esclarecer esse assunto. As conferências vêm sendo promovidas pela Fundação Estadual de Política Indigenista (Fepi/ Coiab).

Na região Norte criou-se a Rede Norte de Propriedade Intelectual, Biodiversidade e Conhecimento Tradicional, que envolve pesquisadores do Instituto Nacional de Pesquisas da Amazônia (Inpa), a Universidade do Pará, ONGs e povos indígenas.

Em dezembro de 2001 um grupo de pajés reunido em São Luís do Maranhão redigiu uma carta sobre conhecimentos tradicionais, e esse é um dos documentos mais importantes na definição e reflexão sobre a proteção desses conhecimentos. E outros encontros vêm dando continuidade a esse processo.

\section{O conhecimento e a repartição de benefícios}

Todo conhecimento indígena é coletivo, e assim ele é reconhecido na Constituição. Não é conhecimento privado nem público, portanto precisa ter uma regra diferenciada de proteção. O Estado brasileiro precisa saber respeitar e praticar o que dizem a Convenção da Diversidade Biológica, ratificada pelo Brasil, e a Convenção 169 da Organização Internacional do Trabalho (OIT), que se referem aos direitos indígenas.

A medida provisória precisa evoluir e se transformar em lei, reafirmando a participação dos detentores de conhecimentos. OMMA está fazendo consulta pública sobre o assunto este ano, mas já existe uma lei tramitando no Congresso, e isso é falta de respeito. Enquanto estamos conversando sobre como nós queremos que seja essa lei, de repente existe outra sendo aprovada. Mas esse é o Estado brasileiro, democrático mas sem respeito. Os controladores do mercado não gostam disso, e a comunidade científica também não.

Estamos cientes de que ninguém da sociedade capitalista vai se interessar pelo conhecimento de nosso modo de vida, do dia-a-dia das nossas comunidades. Mas eles estão interessados nos nossos conhecimentos associados às plantas, que são atalhos aos princípios ativos presentes nos materiais com recursos genéticos. Por isso, a lei deve esclarecer definitivamente a questão e garantir que as comunidades possam fazer contratos com empresas, quando ambas as partes concordarem, discutindo direito de imagem e repartição de benefícios.

Todo conhecimento que foi desenvolvido na terra é uma ciência, porque o homem veio ao mundo quando a terra já estava pronta. E o homem estuda para descobrir os segredos da natureza, segundo sua vontade e interesse. O povo indígena desenvolveu seu conhecimento ao longo de milênios de vida na terra, por isso sistematiza esse conhecimento sobre princípios diferentes daqueles uti- 
lizados pelo mundo 'ocidental'. O conhecimento científico é, em nosso modo de entender, construído sobre os conhecimentos tradicionais, e é isso que justifica a repartição de benefícios. Ou seja, os produtos da ciência ocidental nunca surgiram por si.

\section{O Estado brasileiro e a comunidade científica}

A ciência ocidental tem tido dificuldade em reconhecer nossas ciências. Já ouvi representantes da comunidade cientifica dizerem que o conhecimento tradicional indígena atrapalha o desenvolvimento tecnológico do país. Que não vale um centavo. Que o conhecimento tradicional indígena coletivo é público e, portanto, o acesso a ele não deve estar sujeito a regras. A agressão mais antiga atinge a nossa religião: dizem que ela evoca demônios e portanto deve acabar. Mas nenhum desses argumentos é verdadeiro. Eles vêm de pessoas que só querem atrapalhar os direitos humanos. Porque no Brasil toda a coisa pública está sujeita a regras e burocracias intermináveis, tudo para não dar vez aos mais pobres.

Hoje em dia os dois conhecimentos - o dos brancos e o nosso são muito importantes para nós e para o mundo, que está "à beira de um abismo", como já ouvi falar. Portanto precisamos conhecer bem o nosso sistema e também o da sociedade 'envolvente'. Um sistema não pode dominar o outro. Os indígenas precisam conhecer o sistema dessa sociedade que nos envolve, para não serem dominados por ela.

\section{Considerações finais}

Os conhecimentos devem estar voltados para a proteção da vida. Existem diversas tentativas de proteger a floresta, como as Reservas para Desenvolvimento Sustentável, as Unidades de Conservação e as Reservas de Extrativismo Vegetal. Mas a biodiversidade da Amazônia Brasileira mostra que, comparadas a todas essas tentativas, as terras indígenas são as que mantêm a sua floresta de uma forma mais completa, com pouca alteração. São conhecimentos e práticas tradicionais indígenas associados. É o mundo do conhecimento sustentável indígena, que não pode mais ser ignorado.

(Visite o site www.artebaniwa.org.br) 


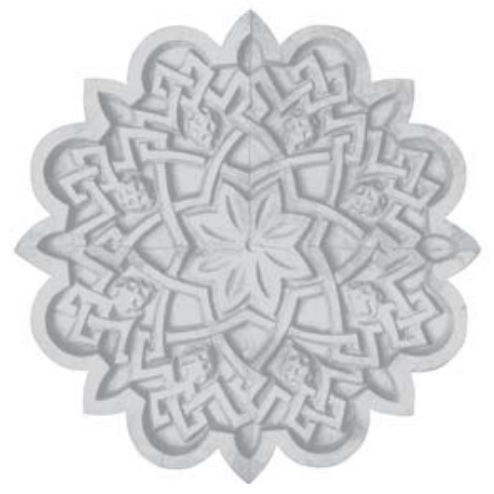

